\title{
The Design and Research of Electric Firebox Reflector Curve Optimization
}

\author{
Yingping Cao \\ School of Mechanical Engineering, North China Electric Power University (baoding), Hebei Baoding \\ 071000, China
}

1165278032@qq.com

Keywords: electric firebox,directional transmission, reflectors, curve,optimal design.

\begin{abstract}
Traditional electric firebox design is unreasonable because the sheeting curve on the grid plate to cause the electric firebox lateral support bars blocking the infrared light almost $1 / 2$, so that the heat pipe heat underutilized. To solve these problems, we use radiotherapy principle theoretical studies on the mirror curve traditional electric firebox and the use of AutoCAD optimized directional reflected light effect curve analysis, the original issue of the loss of the heat pipe in the bottom part of the light, the use of reflection principle be reflected upwards and through a certain angle so that the reflection from the gap at the top of the grid plate, the grid plate thereby reduce the lower surface of lateral support bars blocking infrared light and heat loss to improve energy efficiency.
\end{abstract}

\section{Introduction}

Electric furnaces are combined with modern electric technology and advanced technology in the traditional firebox on and development of the latest technology products, popular to say can be used to bake a wet and dry out shoes, insoles, clothing, and blankets and so on, and can used to room heating feet or electric furnaces [1]. Electric firebox of infrared light emitted by the quartz tube out of the light emitted by electric firebox grid gap out, the light shines on the body generates heat. Reflector plate is an important component of electric firebox affecting electric firebox infrared light utilization efficiency, typically with a thickness of $1 \mathrm{~mm}$ made of aluminum material, due to the direct impact of the reflecting plate curve reflection efficiency, it is necessary to conduct in-depth study of its shape [2].

\section{The optimum design for the reflective plate}

\subsection{Optimization Design Principle}

According to market research, the daily small household electric firebox has seven grid gap and a lamp. In order to effectively utilize the light emitted by the lamp heat reflective sheet placed under the heat lamp, so that the original due to the blocking of the grid at the bottom of all of the light output from the power grid firebox gap, when the sheeting is placed right angle, heat lamp tube made of light will be utilized to the fullest.

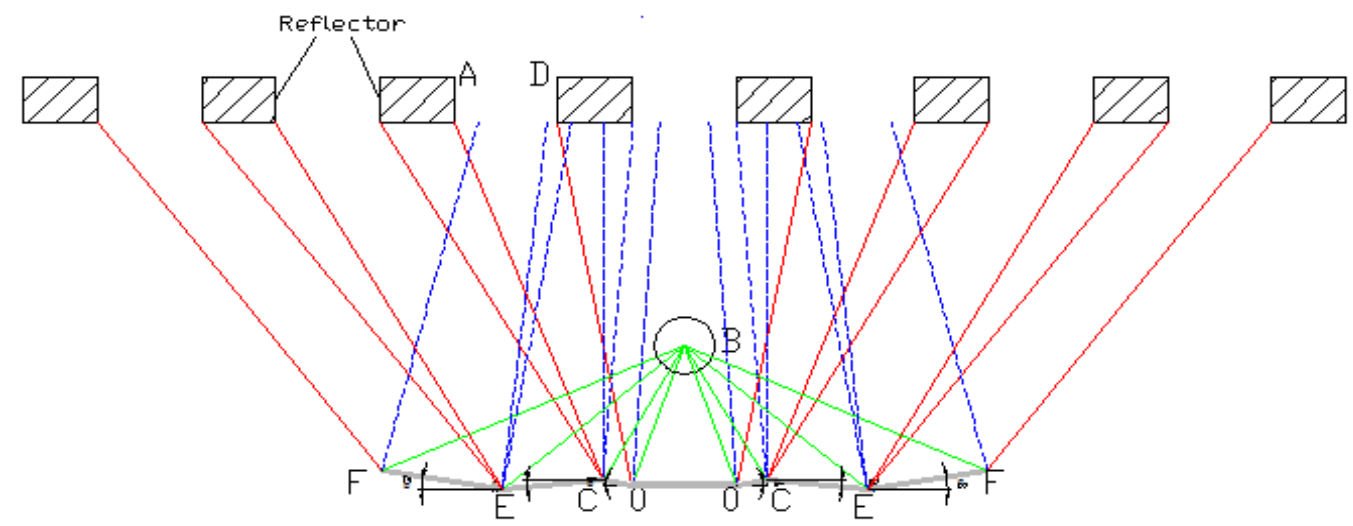

Figure 1: The light-reflecting sheeting border schematics 


\subsection{Theoretical calculations}

Place each sheeting angle $\theta$ and its size is determined by the boundary conditions of the grid gap boundary is shown below:

Legend:



Take sheeting $\mathrm{CO}$ analysis, when $\mathrm{O}$ points have been identified, the sheeting angle $\theta$ by the incident ray BO (B for the lamp) and reflected light OD determined; CO's length by the incident rays $\mathrm{BC}$ and CO reflected light CA OK[3]. A, D two-point gap at both ends of the grid points is 1 . Such analysis is to make a light bulb $\mathrm{B}$ toward sheeting $\mathrm{CO}$ voids all reflected back to the grid 1 . Similarly, the reflective film and sheeting EC FE is thus determined. OO sheeting horizontally on the tube just below.

A detailed analysis of the theoretical derivation of the following, still with $\mathrm{CO}$ sheeting for example.

According to the reality of electric firebox to the relevant parameters:Raster gap width: $A D=$ 35mm; wood aspect: 25X16mm; lamp from the bottom: h1 = 50mm; electrical fire box height: $\mathrm{h} 2=$ 130mm.Take an enlarged portion of OC in Fig. 1,as followings:



Figure 2: Schematic reflector (enlarged)

Take the points of $\mathrm{O}$ to the apex, the establishment of a Cartesian coordinate system $\mathrm{XY}$ axis. First you have to determine $\theta, \theta$ determined after, also will determine where the straight line OC; then determine the $\mathrm{C}$ point after point $\mathrm{C}$ is determined, $\mathrm{OC}$ line is the location where the mirror $\mathrm{OC}$ is also OK.

1)Analysis of $\theta$ Solution

$\theta^{13^{\prime}}=\arctan \left(\frac{l}{h 1}\right)=70.71^{\circ}$; because of he position A, B, O points have been identified, we can get $\angle A O B=19.25^{\circ} ; \theta^{11^{\prime}}=\theta^{12^{\prime}}=\frac{1}{2} \angle A O B=9.645^{\circ}$; it can be obtained from the geometric relationship equal to the angle $\theta 1$ with the normal height axis $\theta^{14^{\prime}}, \theta^{14^{\prime}}=90^{\circ}-\theta^{13^{\prime}}-\theta^{12^{\prime}}=9.645^{\circ}$, so $\theta=9.645^{\circ}$;

2)The determine the point $C$

By the triangle OO'B can be calculated $O B=\sqrt{l^{2}+h_{1}^{2}}=52.94 \mathrm{~mm}$,because of $h_{2}=130 \mathrm{~mm}$, $l_{1}=77.5 \mathrm{~mm}, \Delta h=h_{2}-h_{1}=80 \mathrm{~mm}$, form the figure we can know $\theta_{14}=\theta_{13}$,

$$
\begin{aligned}
& \theta_{11}=\theta_{12} . \mathrm{OC}=O C=l_{0} ; C B=\sqrt{\left(l_{0} \cos \theta+l\right)^{2}+\left(h_{1}-l_{0} \sin \theta\right)^{2}} \\
& \cos \theta_{13}=l_{0}^{2}+\left(l_{0} \cos +l\right)^{2}+\left(h_{1}-l_{0} \sin \theta\right)^{2}-\left(l^{2}+h_{1}^{2}\right)(2) \\
& \theta_{12}+\theta_{14}=\frac{\pi}{2}
\end{aligned}
$$




$$
\begin{aligned}
& A C=\frac{h_{2}-l_{0} \sin \theta}{\sin \left(\theta_{14}+\theta\right)}(4) \\
& \cos 2 \theta_{11}=\frac{A C^{2}+B C^{2}-\left(l_{1}^{2}+\Delta h^{2}\right)}{2 A C \bullet B C}
\end{aligned}
$$

From the above formula can be obtained five variables which is $l_{0}, A C, B C, \theta_{11}, \theta_{3}$, we can get $l_{0}$ values and determine the position of point $\mathrm{C}$,so the $\mathrm{OC}$ sheeting can be determine.Similarly,use the above method of obtaining sheeting FE and EC, $(\theta, x, y)$ represents the angle and the spatial position of each point in the Cartesian coordinate system.Point $C$ is calculated as $\left(9.645^{\circ}, 10,1.7\right)$, point $E$ is(-171 $\left.{ }^{\circ}, 43.86,-1.86\right)$,point $\mathrm{F}$ is $\left(10^{\circ}, 84.31,5.2\right)$.

\subsection{AutoCAD[4] Simulation Analysis}

Legend:

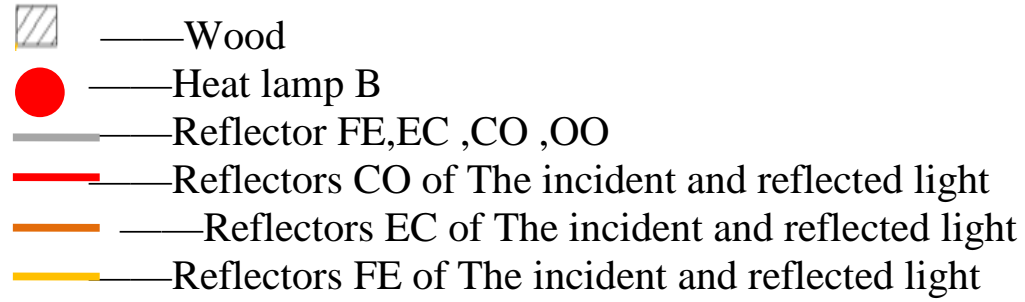

Figure 3 shows.After install the reflector,the light which is transmitted to the bottom of the electric firebox almost all been reflected into the electric grid gap at the top of the firebox by optimized reflector.



Figure 3: The renderings of optimized reflector device

\section{The experimental results and analysis}

The following is the thermal imaging equipment’s of Fluke Ti20 Image imaging picture.

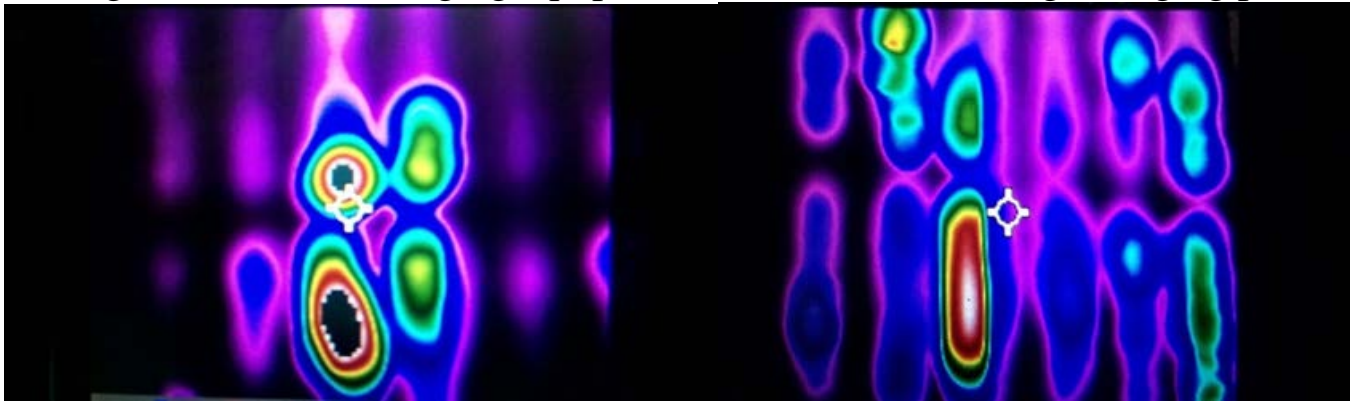

Figure 4:Improved ago

Figure 5: The improved

Improved ago,we can see clearly the temperature field[5] of imaging figure at figure 4.Image color is suddenly dark in the area outside.The temperature suddenly dropped in the center of tube and the unit distance of the temperature difference is bigger on both sides.Temperature field is uneven distribution and heat concentrated on grid location.Compared with the previous,the temperature field 
of imaging diagram is shown in figure 5 after transforming.Image color gradually dim in the area outside and the temperature is gradually dropped.The temperature difference is very small in unit distance and temperature field's distribution is uniform.To form a relatively homogeneous temperature field is beneficial.The purpose of saving energy and reducing consumption arrived.

\section{Summary}

By calculating the theoretical model and through the analysis of optimization curve in AutoCAD,optimization curve can effectively solve the problem of the low energy utilization due to the grid plate transverse wood block obstructs in the electric fire box.The electric fire box optimization curve is only for the electric fire box. As the change of electrical fire box body size, change the different model parameters, using model still can get the best corresponding curve.

\section{References}

[1].Informationon:http://baike.baidu.com/link?url=9Vm0HDWLlU7Qjj_5D1PiPCBH1bH2S-Ddwg JSfUlzkpqk4QMErjslUb9zq1oxJ4W0YcT45IEHaowbu97u85d8tq.

[2] Deng Haiying new type of infrared reflective plate Curve woks and optimized design. Liuzhou Teachers College. Vol. 28 (2013) No. 3, p.142-148.

[3]. Wu Jian, Yan Teachers, optical principles tutorial. National Defense Industry Press, 2007.01, P.26-38.

[4] Huang heping , AutoCAD2008 practical tutorials, Tsinghua University Press, 2012.4 P.1-223.

[5] Tao Wenquan, heat transfer Northwestern Polytechnical University Press, 2006.12, P.4-18. 